\title{
SECOND ORDER SLIDING MODE CONTROLLER DESIGN WITH OPTIMUM CHARACTERISTIC EQUATION FOR QUADROTORS
}

Umut Tilki* Electrical and Electronics Engineering, Faculty of Engineering, Suleyman Demirel University, Turkey, umuttilki@sdu.edu.tr

(iD https://orcid.org/ 0000-0002-8988-787X)

Ali Can Erüst Electrical and Electronics Engineering, Faculty of Engineering, Mugla Sitki Kocman University, Turkey, alicanerust@mu.edu.tr

(iDhttps://orcid.org/0000-0002-6619-1431)

Received: 21.08.2020, Accepted: 30.12.2020

Research Article

*Corresponding author DOI: $10.22531 /$ muglajsci.783506

\begin{abstract}
Nowadays, small structured micro unmanned aerial vehicles (UAV's) with four-rotor appears in military and civilian applications. As the usage of these vehicles becomes widespread, the development of controller structures which allow the UAV's to follow a specified trajectory precisely is a new area of interest for researchers. In this work, nonlinear mathematical model of a four-rotor UAV is obtained. In order to obtain the mathematical model of UAV Newton-Euler equations are used. In the trajectory tracking system of this vehicle, second order sliding mode controller (SOSMC) is designed. Inside of the controller, control process is divided into two subsystems in order to provide position and attitude control. SOSMC is applied to the fully actuated and under actuated subsystems individually. In the next step, coefficients of the SOSMC is determined with optimum characteristic equation. Based on the reference study, boundaries of the predefined characteristic equation is obtained. Later, appropriate values are observed. In final part, simulation results are obtained, and the results are compared with the reference study. As a result, Optimum Characteristic equation results proved its robustness according to the smaller steady state error and more precise flight performance in trajectory. In this study simulation results are obtained using Simulink/MATLAB environment.
\end{abstract}

Keywords: Quadrotor, Mathematical Modeling, Sliding Mode Control (SMC), Trajectory Tracking

\section{QUADROTORLAR İÇIN OPTIMUM KARAKTERISTIK DENKLEMLİ İKINCİ DERECEDEN KAYAN KIPLII DENETLEYICI TASARIMI}

Özet

Son zamanlarda, düşük boyutlarda kullanılan dört motorlu mikro insansız hava araçları (IHA) askeri ve sivil uygulamalarda karşımıza çıkmaktadır. Kullanım alanlarının giderek genişlemesi ile birlikte, yörünge takibinde daha hassas uçuşların gerçekleștirilmesi problemleri adına geliștirilen kontrol yapıları araştırmacılara yeni alanlar açmaktadır. Bu amaçlar doğrultusunda, ilk olarak bu çalışmada dört motorlu İHA'nın doğrusal olmayan matematiksel modeli NewtonEuler denklemleri ile elde edilmiștir. Yörünge takibinde IHA'ya ikinci dereceden kayan kipli denetleyici (SOSMC) uygulanmıştır. SOSMC yapısı içerisinde pozisyon ve davranış kontrolünün sağlanması için tek durum değişkenli ve çift durum değişkenli alt sistemlere ayrı ayrı uygulanmıştır. Bir sonraki adımda denetleyici katsayıları optimum karakteristik denklem kullanılarak bulunmuştur. Referans çalıșmaya bağlı kalınarak denklemin sınır değerleri elde edilmiş ve en optimum değerler bu sınır değerler içerisinden elde edilmiştir. Son bölümde ise denetleyiciye ait benzetim sonuçları elde edilmiş ve referans çalışma ile karşılaştırılması yapılmıştır. Sonuç olarak, elde edilen şekillere göre Optimum karakteristik denklem sonuçları daha az kalıcı durum hatası üretmiş ve daha yüksek hassasiyetle yörüngeyi takip etmiştir. Bu sayede elde edilen son kontrol yapısı gürbüzlüğünü kanıtlamıştır. Bu çalışmada elde edilen benzetim sonuçları Simulink/MATLAB ortamında gerçekleştirilmiştir.

Anahtar Kelimeler: Quadrotor (İHA), Matematiksel Modelleme, Kayan Kipli Denetleyici, Yörünge Takibi

Cite

Tilki, U. and Erust, A. C., (2020). “Second Order Sliding Mode Controller Design with Optimum Characteristic Equation for Quadrotors", Mugla Journal of Science and Technology, 6(2), 150-157. 


\section{Introduction}

From last decade to now, Micro Unmanned Aerial Vehicles (micro UAV's) have gained enormous interest when compared to the other robotics applications. There are two major reasons behind this growing interest. One of them is having reduced mechanical complexity in hardware part and the other one is recent developments in micro electromechanical systems (MEMS) which causes the minimization of the mechanical part and fast decision-making mechanism. Besides of this interest UAV's have started to use in many new areas. In military applications these air vehicles are used for mapping of an unknown dangerous and dirty areas, border security, search and rescue operations etc. In civilian applications these air vehicles are used for cargo services, traffic monitoring, weather monitoring, automatic forest fire detection and cinema industry etc. According to the high precise missions, UAV's require robust control algorithms to successfully complete this mission [1-7].

Quadrotors are one of the most well-known type of micro UAV's. It has four motor with generally rigid symmetric structure and ability to vertical take-off and landing (VTOL). According to the structure, stable airborne flight such as position and attitude tracking achieved with only robust flight algorithms when designing the model-based controllers. Thus, researchers design mathematical model-based controllers, assuming that the quadrotor structure is rigid and symmetrical with respect to the center. To successfully track position and attitude for quadrotors, there are some control approaches in the literature. The control algorithms are taken into account with respect to the linearity of the controller approaches [8-10].

PID is one of the most well-known control techniques for robotics and also quadrotors. Main advantages of PID controller are, easy to understand and adopt to the system. Besides of this simplicity, it produces satisfying results. Bolandi et. al. presented a control approach for stabilization and disturbance rejection for attitude control of quadrotor [11]. While tuning the PID controller parameters an analytical optimization method is used. Argentim et. al. presented a comparison for a quadrotor control namely PID, Linear Quadratic Regulator (LQR) and PID tuned with LQR loop [12]. In the simulation part 10 different attitude are discussed. In their results, they found out LQR type of controller was robust and produce small steady state error. Hence, they had big transition delay. PID controllers were produced fast responses to the system but robustness of the overall system was pure. While assigning the PID controller gains there are several methods, and these methods give satisfying results. For this reason, these controllers are not enough for high precise flights [13].

While deriving the quadrotor's equation of motion, there are nonlinearities inside of the attitude and position movements. Beside of the nonlinearities, quadrotor systems have parametric uncertainties and many disturbance effects such as wind, sensor misreading and noises, propeller deflection, center of gravity (cog) shift etc. When these nonlinearities and uncertainties are considered, nonlinear controller approaches produce more promising responses than traditional linear control algorithms. Lippiello et al. searched a failure of one of the motors on quadrotor [14]. In this fault tolerant control method scenario, one motor turned off. Later, simulations were validated the proposed backstepping control for safely landing. The Sliding Mode Control (SMC) method is one of the robust controllers in the literature [15-17]. Different type of SMC methods is proposed for quadrotors trajectory tracking, attitude and position control. Xu et al. used SMC to control quadrotor attitude and position while quadrotor was under disturbance effect [18]. In literature, chattering is major issue for SMC. Based on switching control law of SMC, chattering occurs in the control signals and it may cause permanent breakdown on the system. There are several methods to eliminate chattering phenomena. Boundary layer extension is one of well-known technique in literature. Hence, Yang et al. successfully eliminated the chattering without using any boundary extension function [19]. Overall system stability is guaranteed with Lyapunov stability theorem. Zhang et al. proposed a second order SMC (SOSMC) method to control attitude and position [20]. In that reference study quadrotor control algorithm divided into two subsystems. To ensure overall system stability SMC coefficients are determined with pre-chosen characteristic equation.

In this work, SOSMC is designed with a new characteristic equation. It is foreseen that the proposed characteristic equation will provide less oscillations and better flight stability with less steady state error since its step response is better than the reference characteristic equation. To observe less oscillation and better flight stability on trajectory, step responses are examined. According to the proposed characteristic equation, controller coefficients are obtained, and the simulation results are proved that proposed characteristic equation gives better results than reference trajectory with respect to sustained oscillations and steady state errors on trajectory tracking.

The rest of the paper is organized as follow. In the second part, mathematical model of system and dynamic equation derivations are given. Second order sliding mode controller design and required equations which demonstrate the controller and guarantee system stability is given in section three. In section four the numerical simulation results based on predefined scenario are given. Moreover, according to trajectory performance criteria comparison with reference study [20] are given in this section. In addition to the comparison, proposed controller better flight stability and less oscillation against noises are proved in the results. Concluding remarks are given in Section 5. 


\section{Mathematical Modeling of Flight}

The quadrotor system has four input which are altitude, $\mathrm{x}, \mathrm{y}$, and yaw $(\psi)$ angle and six output $\mathrm{x}, \mathrm{y}, \mathrm{z}$, roll, pitch and yaw. Based on input output relations, the system is called under-actuated.

\subsection{Coordinate Systems and Quadrotor Structure}

Quadrotor has two coordinate systems, one of them is called inertial reference frame and the other one is body fixed frame. Translational motion occurs on the three direction of inertial reference frame $\mathrm{x}, \mathrm{y}, \mathrm{z}$ and the variables $(\phi, \theta, \psi)$ include rotational motion around three axes on the body fixed frame. Fig. 1 is schematic diagram of the quadrotor with four rotors. Two pairs of rotors $(1,3)$ and $(2,4)$ spins opposite directions (Clockwise and Counterclockwise). Thus, the net moment with respect to the center of gravity becomes zero. In addition to this, the roll $(\phi)$ rotation can be obtained by changing the speed of motors two and four, the pitch $(\theta)$ rotation can be obtained by changing the speed of motors one and three, the yaw $(\psi)$ rotation can be obtained by speed differences of neighbor motors. And finally, vertical movements can be obtained by equal speed of four motors. To mathematically describe quadrotor dynamics, system requires two assumptions.

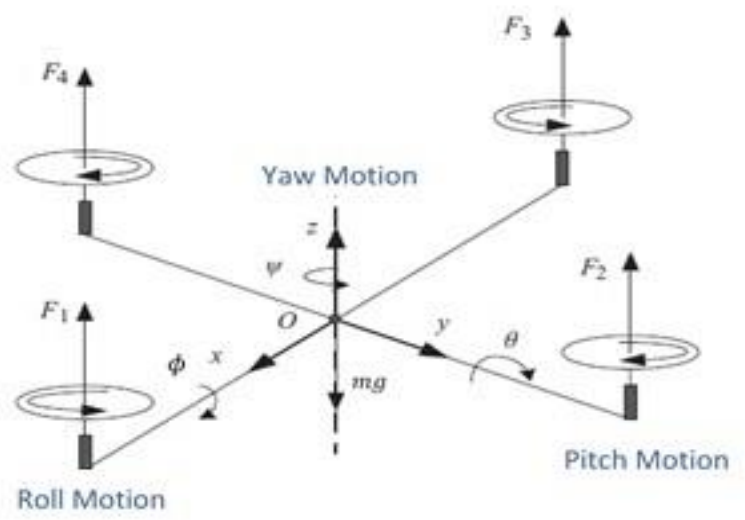

Figure 1. Schematic diagram of the quadrotor.

One of them is the quadrotor has a symmetrical structure and other one is, the quadrotor's structure is rigid. Following subsection describes the dynamics of the quadrotor.

\subsection{Quadrotor Dynamics}

In this section nonlinear dynamical equations of the quadrotor derived by using Newton-Euler method. In here, body fixed frame coordinates are represented by $B\left(O_{x y z}\right)$, while inertial reference frame of coordinates indicated with $E\left(O_{x y z}\right)$. The vector $\eta=\left[\begin{array}{lll}\phi & \theta & \psi\end{array}\right]^{T}$ and the vector $\xi=\left[\begin{array}{lll}x & y & z\end{array}\right]^{T}$ describing the rotorcraft orientation and position in coordinate frames respectively and where, roll $(\phi)$ is angle around $\mathrm{x}$-axis, pitch $(\theta)$ is angle around y-axis and yaw $(\psi)$ is angle around z-axis. These angles are bounded as follows; roll angle $\left(-\frac{\pi}{2}<\phi<\frac{\pi}{2}\right)$ pitch angle $\left(-\frac{\pi}{2}<\theta<\frac{\pi}{2}\right)$ and yaw angle by $(-\pi<\psi<\pi)$. With the help of this boundaries, quadrotor can avoid unwanted motions in the airborne.

Rotation matrix is given in equation (1) and it is used for transformation from inertial reference coordinates to body fixed coordinates. By the help of this equation, quadrotor's angle to position relation is extracted.

$$
\left[R_{B}^{E}\right]=\left[\begin{array}{ccc}
s \theta c \psi & c \psi s \theta s \phi-s \psi c \phi & c \psi s \theta c \phi+s \psi s \phi \\
s \theta s \psi & s \psi s \theta s \phi+c \psi c \phi & s \psi s \theta c \phi-c \psi s \phi \\
-s \theta & c \theta s \phi & c \theta c \phi
\end{array}\right]
$$

$\mathrm{R}$ is an orthogonal matrix with determinant equals to 1 . In here, s(.) and c(.) correspond sine and cosine functions respectively. Translational kinematics from body fixed frame to inertial frame is as follows.

$$
v_{E}=R_{B}^{E} \cdot v_{B}
$$

In here $v_{E}$ and $v_{B}$ represents linear velocities on the inertial frame and body frame, respectively. Rotational kinematics defined as follows between inertial frame and body fixed frame.

$$
\left[\begin{array}{c}
\dot{\phi} \\
\dot{\theta} \\
\dot{\psi}
\end{array}\right]=\left[\begin{array}{ccc}
1 & \sin \phi \tan \theta & \cos \phi \tan \theta \\
0 & \cos \phi & -\sin \phi \\
0 & \sin \phi \sec \theta & \cos \phi \sec \theta
\end{array}\right]\left[\begin{array}{l}
p \\
q \\
r
\end{array}\right]
$$

In Equation (2) and (3) velocity relation both in inertial frame and body frame is described. Final step of deriving quadrotor's nonlinear mathematical model is acceleration on both inertial coordinates and body coordinates. Equations (4), (5) represent the NewtonEuler equation.

$m \ddot{P}=g+R \tau_{z}$

$\tau_{B}=J \dot{\gamma}+\gamma x(J \gamma)$

In these equations (4-5) P matrix represents the inertial position and $\gamma$ shows the angular velocities. Let $X=$ $\left[x_{1}, x_{2}, x_{3}, x_{4}, x_{5}, x_{6}, x_{7}, x_{8}, x_{9}, x_{10}, x_{11}, x_{12}\right]=$ $[\phi, \dot{\phi}, \theta, \dot{\theta}, \psi, \dot{\psi}, x, \dot{x}, y, \dot{y}, z, \dot{z}] \in \mathcal{R}^{12}$ represents the state variable of nonlinear quadrotor system. Overall state space representation can be seen in equation (6).

$$
\left\{\begin{array}{c}
\dot{x}_{1}=x_{2} \\
\dot{x}_{2}=\ddot{\phi}=a_{1} x_{4} x_{6}+a_{2} x_{4}+a_{3} x_{2}+b_{1} \tau_{\phi} \\
\dot{x}_{3}=x_{4} \\
\dot{x}_{4}=\ddot{\theta}=a_{4} x_{2} x_{6}+a_{5} x_{2}+a_{6} x_{4}+b_{2} \tau_{\theta} \\
\dot{x}_{5}=x_{6} \\
\dot{x}_{6}=\ddot{\psi}=a_{7} x_{2} x_{4}+a_{8} x_{6}+b_{3} \tau_{\psi} \\
\dot{x}_{7}=x_{8} \\
\dot{x}_{8}=\ddot{x}=a_{9} x_{8}+\frac{\tau_{z}}{m}\left(C_{x 1} S_{x 3} C_{x 5}+S_{x 1} S_{x 5}\right) \\
\dot{x}_{9}=x_{10} \\
\dot{x}_{10}=\ddot{y}=a_{10} x_{10}+\frac{\tau_{z}}{m}\left(C_{x 1} S_{x 3} S_{x 5}-S_{x 1} C_{x 5}\right) \\
\dot{x}_{11}=x_{12} \\
\dot{x}_{12}=\ddot{z}=a_{11} x_{12}+\frac{\tau_{z}}{m}\left(C_{x 1} C_{x 3}\right)-g
\end{array}\right.
$$

In this state-space representation, $a_{1}=\frac{J_{y}-J_{z}}{J_{x}}, a_{2}=\frac{\Omega_{r} J_{r}}{J_{x}}$, $a_{3}=\frac{-K_{1} l}{J_{x}}, a_{4}=\frac{J_{z}-J_{x}}{J_{y}}, a_{5}=\frac{-\Omega_{r} J_{r}}{J_{y}}, a_{6}=\frac{-K_{2} l}{J_{y}}, a_{7}=\frac{J_{x}-J_{y}}{J_{z}}$, 
$a_{8}=\frac{-K_{3} l}{J_{z}}, a_{9}=\frac{-K_{4}}{m}, a_{10}=\frac{-K_{5}}{m}, a_{11}=\frac{-K_{6}}{m}, b_{1}=\frac{l}{J_{x}}, b_{2}=$ $\frac{l}{J_{y}}, b_{3}=\frac{1}{J_{z}}$

In the state equation (6) $\mathrm{m}$ denotes the quadrotor mass, $J_{x}, J_{y}, J_{z}$ denotes the inertia force along the inertial reference coordinates. $l$ represents the distance from motor the center of gravity (cog) of quadrotor and it is also used in below equation. $K_{i}(i=1,2,3 \ldots)$ indicates the disturbance effect on the quadrotor. The relationship between the torques along the axes and angular velocities on the rotors are given by Equation (7).

$\left[\begin{array}{l}u 1 \\ u 2 \\ u 3 \\ u 4\end{array}\right]=\left[\begin{array}{l}\tau_{z} \\ \tau_{\phi} \\ \tau_{\theta} \\ \tau_{\psi}\end{array}\right]=\left[\begin{array}{cccc}b & b & b & b \\ l b & 0 & -l b & 0 \\ 0 & -l b & 0 & l b \\ -k & k & -k & k\end{array}\right]\left[\begin{array}{l}\omega_{1}^{2} \\ \omega_{2}^{2} \\ \omega_{3}^{2} \\ \omega_{4}^{2}\end{array}\right]$

In here, $\mathrm{k}$ represents the lift coefficients of the rotors and b represents air dragging coefficients.

\section{Flight Controller Design}

In this section, mathematical modelling of the second order sliding mode controller demonstrated. Flight controller algorithm divided into two subsystem which are fully actuated and under actuated subsystem. Overall trajectory tracking control design and state variables can be seen in Figure 2.

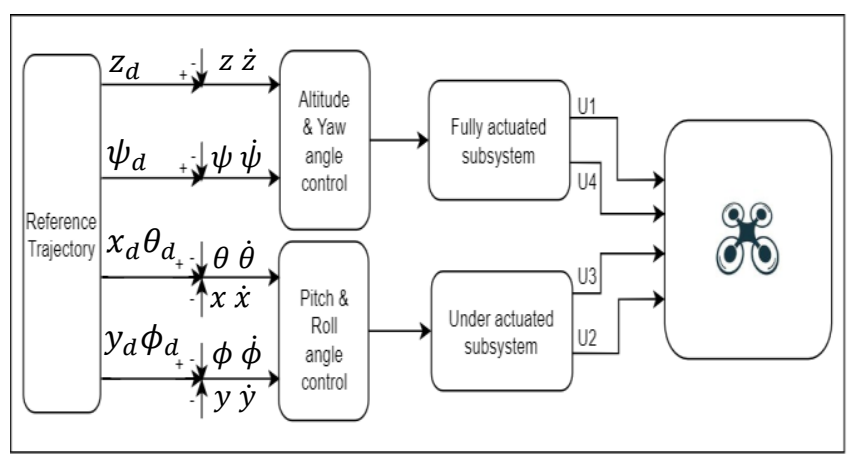

Figure 2. Quadrotor control design.

\subsection{Fully Actuated Subsystem Control}

This section describes the fully actuated subsystem control algorithm based on second order sliding mode controller. The purpose is to ensure state variables $\left[x_{5}, x_{11}\right]$ converge to the desired values $\left[x_{5 d}, x_{11 d}\right]$.

The sliding surface equations for the fully actuated subsystem is expressed in equation (8) and equation (9).

$s_{1}=c_{z}\left(x_{11 d}-x_{11}\right)+\left(\dot{x}_{11 d}-\dot{x}_{11}\right)$

$s_{2}=c_{\psi}\left(x_{5 d}-x_{5}\right)+\left(\dot{x}_{5 d}-\dot{x}_{5}\right)$

In this equation $c_{z}$ and $c_{\psi}$ are the coefficients of the sliding surface equation. In the literature there are different types of sliding surface reaching law [15]. To make the system response as fast as possible, exponential reaching law is considered. Proposed exponential reaching law selected as $\dot{s}_{i}=-\varepsilon_{i} \operatorname{sgn}\left(s_{i}\right)-$ $n_{i} s_{i}$. When the reaching law is applied to the sliding surface new control input signals $u_{1}$ and $u_{4}$ are extracted. Control input $u_{1}$ and $u_{4}$ can be seen in equation (10) and equation (11).

$u_{1}=m \cdot \frac{c_{Z}\left(x_{11 d}-x_{11}\right)+\dot{x}_{12}+d_{1}+\varepsilon_{1} \operatorname{sgn}\left(s_{1}\right)+n_{1} s_{1}}{\cos x_{1} \cos x_{3}}$

$u_{4}=J_{z}\left(c_{\psi}\left(x_{5 d}-x_{5}\right)+\dot{x}_{6}+d_{2}+\varepsilon_{2} \operatorname{sgn}\left(s_{2}\right)+n_{2} s_{2}\right)$

where the $d_{1}=K_{3} \dot{x}_{11} / m$ and $d_{2}=K_{6} \dot{x}_{5} / J_{z z}$ and $\varepsilon_{1}, \varepsilon_{2}, n_{1}, n_{2}>0$. For the fully actuated subsystem control input equations are generated.

\subsection{Under Actuated Subsystem Control}

This section describes the under actuated subsystem control algorithm based on second order sliding mode controller and the aim is to ensure state variables $\left[x_{1}, x_{7}\right]$ and $\left[x_{3}, x_{9}\right]$, converge to the desired values $\left[x_{1 d}, x_{7 d}\right]$ and $\left[x_{3 d}, x_{9 d}\right]$.

The sliding surface equations for the under actuated subsystem is expressed as in the following equations.

$s_{3}=c_{1}\left(\dot{x}_{7 d}-\dot{x}_{7}\right)+c_{2}\left(x_{7 d}-x_{7}\right)+c_{3}\left(\dot{x}_{3 d}-\dot{x}_{3 d}\right)+$

$c_{4}\left(x_{3 d}-x_{3}\right)$

$s_{4}=c_{5}\left(\dot{x}_{9 d}-x_{9}\right)+c_{6}\left(x_{9 d}-x_{9}\right)+c_{7}\left(\dot{x}_{1 d}-\dot{x}_{1}\right)+$

$c_{8}\left(x_{1 d}-x_{1}\right)$

Exponential reaching law is applied to the under actuated subsystem sliding surfaces and new control signals for $u_{2}$ and $u_{3}$ are obtained.

$\dot{s}_{3}=c_{1}\left(\dot{x}_{8 d}-\dot{x}_{8}\right)+c_{2}\left(\dot{x}_{7 d}-\dot{x}_{7}\right)+c_{3}\left(\dot{x}_{4 d}-\dot{x}_{4}\right)+$

$c_{4}\left(\dot{x}_{3 d}-\dot{x}_{3}\right)$

$\dot{s}_{4}=c_{5}\left(\dot{x}_{10}-\dot{x}_{10}\right)+c_{6}\left(\dot{x}_{9 d}-\dot{x}_{9}\right)+c_{7}\left(\dot{x}_{2 d}-\dot{x}_{2}\right)+$

$c_{8}\left(\dot{x}_{1 d}-\dot{x}_{1}\right)$

Based on the exponential reaching law and quadrotor equation of motion control signals of $u_{2}, u_{3}$ extracted as follows.

$$
\begin{aligned}
u_{3}= & \frac{J_{y}}{l}\left(\frac{c_{1}}{c_{3}}\left(\dot{x}_{10}-\dot{x}_{10}\right)+\frac{c_{2}}{c_{3}}\left(\dot{x}_{9 d}-\dot{x}_{9}\right)+\dot{x}_{2 d}+\frac{c_{4}}{c_{3}}\left(\dot{x}_{1 d}-\dot{x}_{1}\right)+\right. \\
& \left.d_{3}+\frac{1}{c_{3}}\left(\varepsilon_{3} \operatorname{sgn}\left(s_{3}\right)+n_{3} s_{3}\right)\right) \\
u_{2}= & \frac{J_{x}}{l}\left(\frac{c_{5}}{c_{7}}\left(\dot{x}_{8 d}-\dot{x}_{8}\right)+\frac{c_{6}}{c_{7}}\left(\dot{x}_{7 d}-\dot{x}_{7}\right)+\dot{x}_{4 d}+\frac{c_{8}}{c_{7}}\left(\dot{x}_{3 d}-\dot{x}_{3}\right)+\right. \\
& \left.d_{4}+\frac{1}{c_{7}}\left(\varepsilon_{4} \operatorname{sgn}\left(s_{4}\right)+n_{4} s_{4}\right)\right)
\end{aligned}
$$

In these equations; $d_{3}=-\frac{\dot{x}_{1} \dot{x}_{5}\left(J_{z}-J_{x}\right)}{J_{y}}+K_{5} l \dot{x}_{3} / J_{y}$ and $d_{4}=-\frac{\dot{x}_{3} \dot{x}_{5}\left(J_{y}-J_{z}\right)}{J_{x}}+K_{4} l \dot{x}_{1} / J_{x}$ and $\varepsilon_{3}, \varepsilon_{4}, n_{3}, n_{4}>0$.

Last part of the second order sliding mode control is calculating of sliding surface coefficients and make sure the quadrotor system is stable. For stability issue Lyapunov function is chosen as $V_{i}=\frac{1}{2} s_{i}^{2}$ and time derivative of $V_{i}$ has to provide the following condition $\dot{V}_{i}=s_{i} \dot{s}_{i}=-\varepsilon\left|s_{i}\right|-n_{i} s_{i}^{2} \leq 0$. Only under this condition all state variables reach and stay on the sliding surface. Therefore, the system stability is guaranteed with Lyapunov function.

According to the SOSMC, control input coefficients are determined with the similar approach in the reference 
[18] by the predefined characteristic equation which is a third order proposed characteristic equation.

Table 1. Overall SOSMC Switching Coefficients

\begin{tabular}{cccc}
\hline Variables & Values & Variables & Values \\
\hline$c_{z}$ & 1 & $c_{\psi}$ & 1 \\
$\varepsilon_{1}$ & 0.8 & $\varepsilon_{2}$ & 0.8 \\
$n_{1}$ & 2 & $n_{2}$ & 2 \\
$c_{1}$ & $12 m /\left(u_{1} \cos \phi \cos \psi\right.$ & $c_{5}$ & $-12 m /\left(u_{1} \cos \psi\right)$ \\
$c_{2}$ & $5 m /\left(u_{1} \cos \phi \cos \psi\right)$ & $c_{6}$ & $-5 m /\left(u_{1} \cos \psi\right)$ \\
$c_{3}$ & 1 & $c_{7}$ & 1 \\
$c_{4}$ & 6 & $c_{8}$ & 6 \\
$\varepsilon_{3}$ & 0.5 & $\varepsilon_{4}$ & 0.5 \\
$n_{3}$ & 5 & $n_{4}$ & 5 \\
\hline
\end{tabular}

\subsection{Switching Coefficient Equation}

This part of the study explains determination of the proposed characteristic equation of the second order sliding mode controller for coefficients.

The characteristic equation and the corresponding coefficients are expressed as follows:

$\lambda^{3}-\left(A_{22}+c\right) \lambda^{2}+\left(c A_{22}-A_{21}-b A_{23}\right) \lambda+c A_{21}-a A_{23}=0$

where;

$A_{21}=-\frac{c_{1}}{c_{3}} \frac{u_{1}}{m} \cos \phi \cos \psi+\frac{c_{2} c_{4}}{c_{1} c_{3}}, A_{22}=\frac{c_{2}}{c_{1}}-\frac{c_{4}}{c_{3}}, A_{23}=\frac{c_{2}^{2}}{c_{1} c_{3}}$,

$a=-\frac{c_{4}}{c_{1}}, b=-\frac{c_{3}}{c_{1}}, c=-\frac{c_{2}}{c_{1}}$

This equation represents the only one state variable of the under actuated subsystem such as $\left[x_{3}, x_{9}\right]$. In order to determine the control input coefficients, a third order equation is employed. The degrees of the characteristic equation should be same with the degree of equation (18). Moreover, the behavior of the quadrotor needs to reach steady state in a fast time with minimum oscillations. Besides overall stability of the whole system is required, so the poles of this $3^{\text {rd }}$ order equation should be in the left half plane in s-domain. Boundaries of the equation are determined based on the reference study and optimum characteristic equation for the controller find out as follows.

$(\lambda+2.2)(\lambda+2.2)(\lambda+0.5)=0$

When equation (18) and (19) compared, final switching coefficients are determined.

$\frac{c_{4}}{c_{3}}=5, \quad \frac{c_{1}}{c_{3}} \frac{u_{1}}{m} \cos x_{1} \cos x_{5}=12, \quad \frac{c_{2}}{c_{3}} \frac{u_{1}}{m} \cos x_{1} \cos x_{5}=5$

Let $c_{3}=1$ and then the rest of the coefficients become:

$$
c_{1}=\frac{12 m}{u_{1} \cos x_{1} \cos x_{5}}, \quad c_{2}=\frac{5 m}{u_{1} \cos x_{1} \cos x_{5}}, \quad c_{4}=5
$$

Avoiding of repeating ourselves extraction of sliding surface coefficients are done only for $s_{3}$, same methodology is also applied to $s_{4}$ and obtained coefficients are found as follows.

$$
c_{5}=\frac{-12 m}{u_{1} \cos x_{5}}, \quad c_{6}=\frac{-5 m}{u_{1} \cos x_{5}}, c_{7}=1, c_{8}=5
$$

Finally switching coefficients of the SOSMC are determined based on optimum and stable $3^{\text {rd }}$ order characteristic equation. Overall switching coefficients of the controller can be seen in following table. On the other hand, for fully actuated subsystem regular SMC is applied to the system as explained above part. Coefficients of the fully actuated subsystem is defined by using trial-error method to obtain stability.

\section{Simulation Results and Discussion}

In this work quadrotor's nonlinear equation of motion is extracted using Newton-Euler method and proposed second order sliding mode controller is applied with optimum characteristic equation. Simulations are done by using Simulink/MATLAB with the version of R2017b using ODE4 solver method and the computer has Intel i7 processor, $500 \mathrm{~Gb}$ SSD.

In the simulation, proposed characteristic equation results and reference characteristic equation results are demonstrated in the same graphs. In addition to this, same yaw angle, disturbance, air drag coefficients are added to the trajectory for fair comparison. As a result, both characteristic equation results compared with the same properties.

At the beginning of the simulation, position on the inertial frame set to $\left[\begin{array}{lll}0 & 0 & 0\end{array}\right] \mathrm{m}$ and on the body frame coordinates set to [ $\left.\begin{array}{lll}0 & 0 & 0\end{array}\right] \mathrm{rad}$. Quadrotor's trajectory determined with respect to the time. Reference trajectory is given as waypoints and time instants demonstrated in Table 2. Quadrotor model parameters and their units which are used during the simulations can be seen in Table 3. These parameters are same with the reference study [18] for fair comparison.

Table 2. Reference Trajectory Points

\begin{tabular}{cccccc}
\hline & $\mathrm{T}=10$ & $\mathrm{~T}=20$ & $\mathrm{~T}=30$ & $\mathrm{~T}=40$ & $\mathrm{~T}=50$ \\
\hline$x_{r}$ & 0.6 & 0.3 & 0.3 & 0.6 & 0.6 \\
$y_{r}$ & 0.6 & 0.6 & 0.3 & 0.3 & 0.6 \\
$z_{r}$ & 0.5 & 0.5 & 0.5 & 0.5 & 0.5 \\
$\psi_{r}$ & 0.5 & 0.5 & 0.5 & 0.5 & 0.5 \\
\hline
\end{tabular}

In Figure 3, 3D trajectory tracking performance of the quadrotor can be seen. The reference trajectory is demonstrated by black line. While the blue line represents the reference study trajectory performance, the red line represents trajectory performance of the proposed controller. 
Table 3. Quadrotor Model Parameters

\begin{tabular}{ccc}
\hline $\mathrm{m}$ & 1.1 & $\mathrm{Kg}$ \\
$\mathrm{L}$ & 0.21 & $\mathrm{~m}$ \\
$\mathrm{~J}_{\mathrm{x}}=\mathrm{J}_{\mathrm{y}}$ & 1.22 & $\mathrm{Ns} / \mathrm{rad}$ \\
$\mathrm{J}_{\mathrm{z}}$ & 2.2 & $\mathrm{Ns} / \mathrm{rad}$ \\
$\mathrm{K}$ & 1 & $\mathrm{Ns} / \mathrm{m}$ \\
$\mathrm{g}$ & 9.81 & $\mathrm{~m} / \mathrm{s}^{2}$ \\
$\mathrm{~b}$ & 5 & $\mathrm{~N} / \mathrm{s}^{2}$ \\
$\mathrm{k}$ & 2 & $\mathrm{~N} / \mathrm{ms}^{2}$ \\
\hline
\end{tabular}

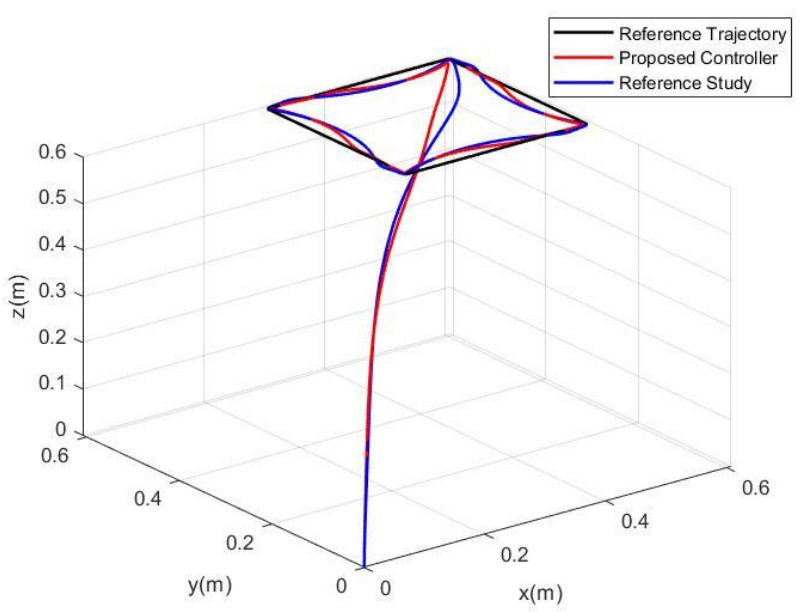

Figure 3. Quadrotor 3D Trajectory Tracking

Proposed optimum characteristic equation has small steady state errors when compared to the reference characteristic equation result. Quadrotor inertial reference frame movements in 2D can be seen in Figure 4,5 and 6 along $\mathrm{x}, \mathrm{y}$ and $\mathrm{z}$ directions. Movements on the inertial frame $\mathrm{x}$ and $\mathrm{y}$ axes have two small scale figures. Small scale figures show the detailed version based on that time. When time is 10 s. on the y axis there is small oscillations which caused by turning point on the axis $\mathrm{x}$ and added yaw movement. Also, at time 20s on the $\mathrm{x}$ axis there is a same oscillation according to the quadrotor trajectory with added noises and yaw movement during the simulation. Through the time 10, 20, 30 and 40 proposed characteristic equation results have less steady state error and less oscillation than reference characteristic equation. With this robustness of the proposed characteristic equation performance against noises proved more stable and it has high precision flight ability when compared with the reference characteristic equation performance. Quadrotor body frame angles can be seen in Figure 7. Even tough, reference trajectory includes simultaneous changes, noises, and orientation distortion in body frame coordinates, second order sliding mode control with optimum characteristic equation performance is also again proved its effectiveness.

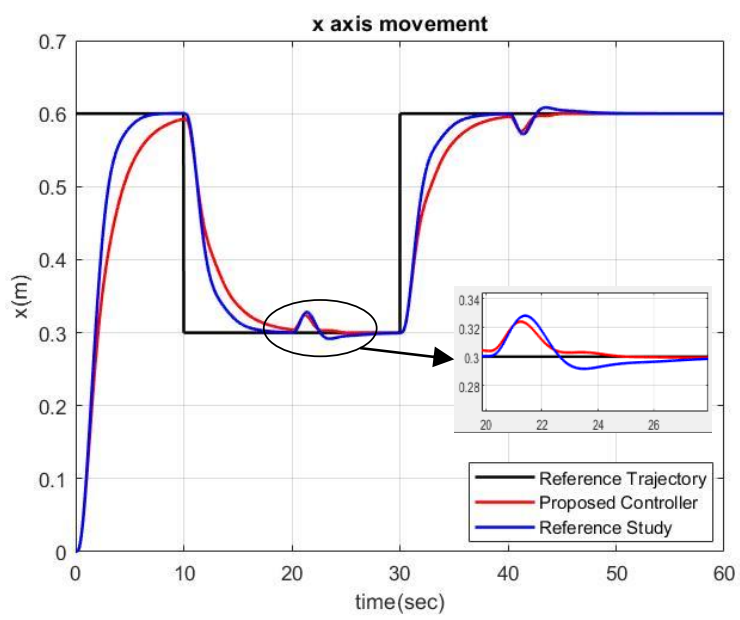

Figure 4. Quadrotor x axis tracking

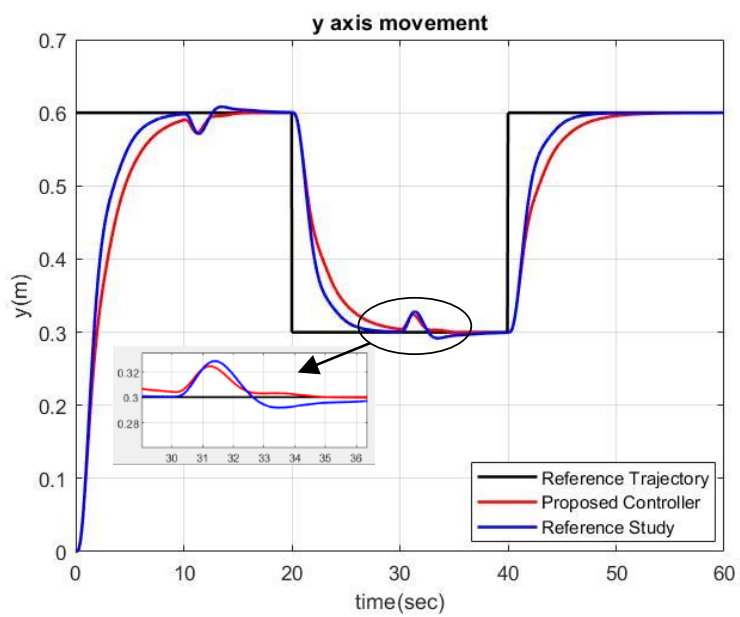

Figure 5. Quadrotor y axis tracking

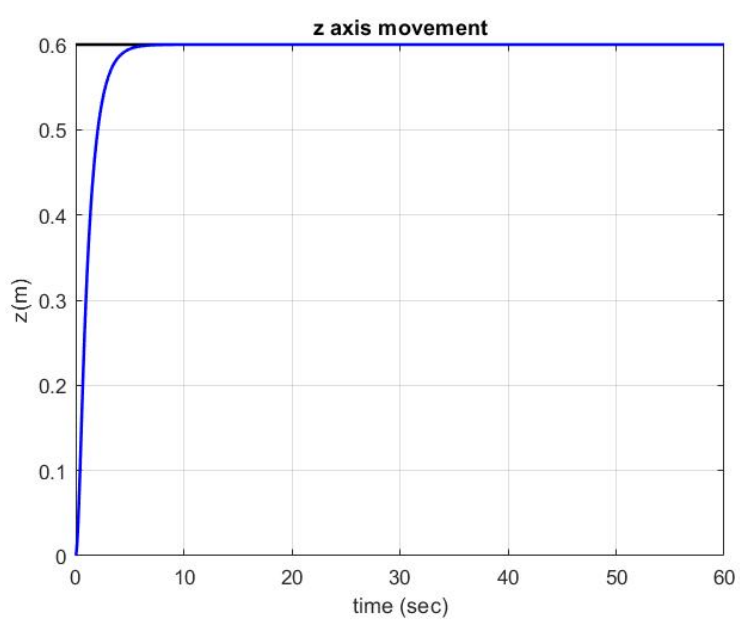

Figure 6. Quadrotor z axis tracking

Linear and angular velocity of the quadrotor can be seen in Figure 8 and 9 respectively. Finally, Figure 10 shows 
that quadrotor control input torques. In addition to trajectory tracking performance improving, chattering effects on the torque inputs are eliminated by using saturation function. Small-scaled figures show detailed $\mathrm{u} 2$ and $\mathrm{u} 3$ torques.
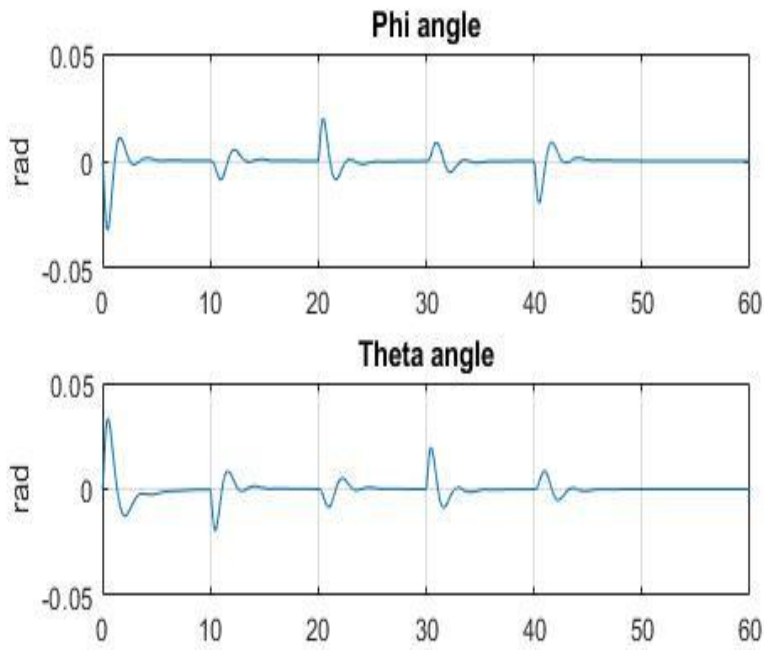

Psi angle

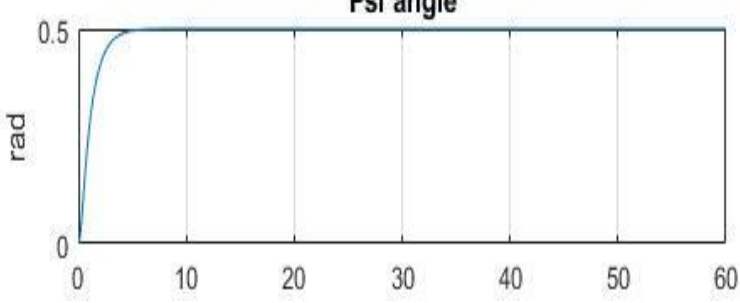

Figure 7. Quadrotor Body Frame Tracking
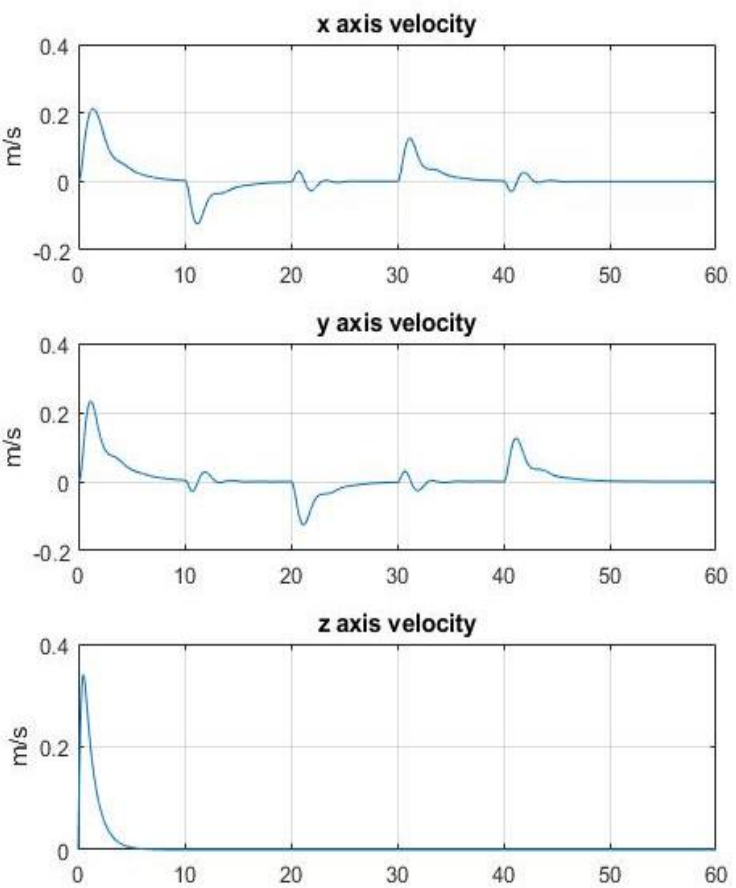

Figure 8. Quadrotor Linear Velocities
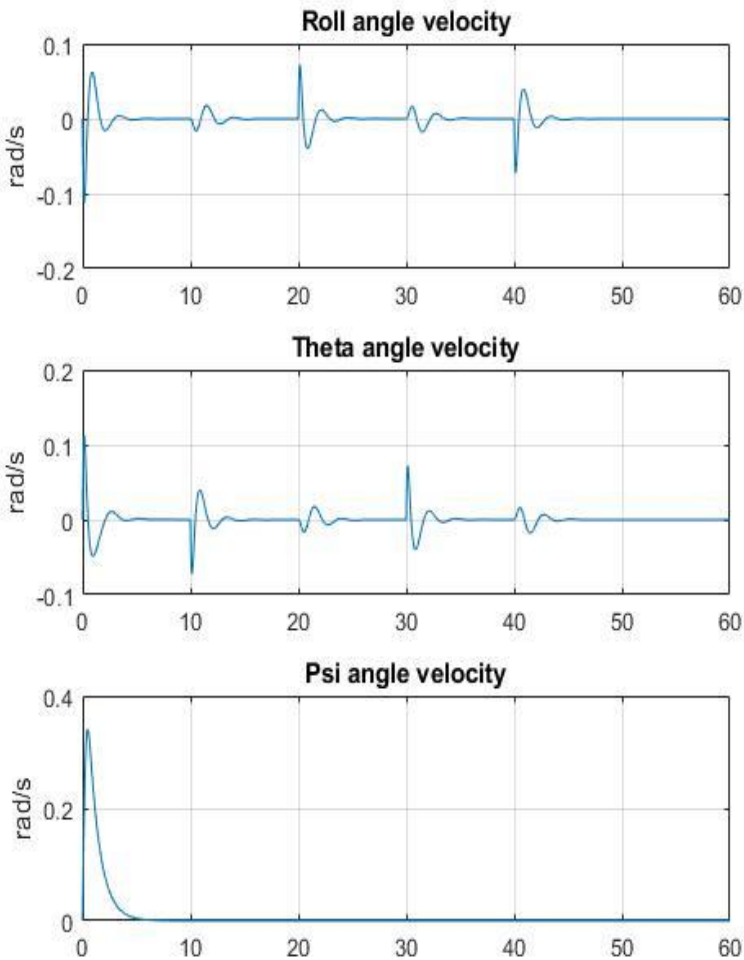

Figure 9. Quadrotor Angular Velocities
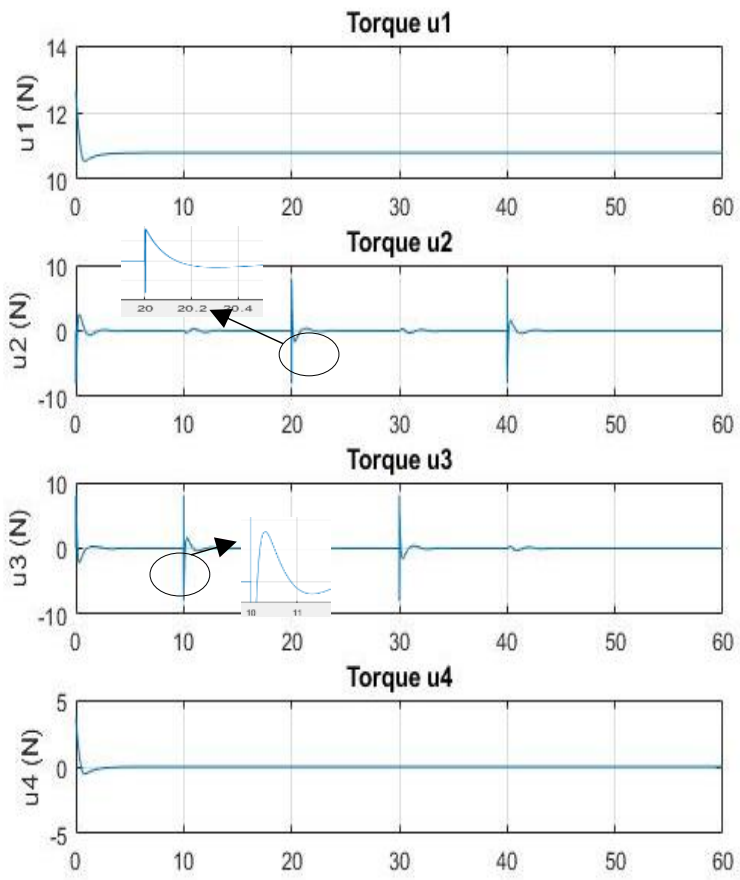

Figure 10. Quadrotor Control Torques

\section{Conclusion}

In this study optimum characteristic equation is proposed for second order sliding mode controller (SOSMC). To obtain characteristic equation, boundaries 
are selected and optimum third order equation is determined based on the refence study. Later, third order optimum characteristic equation and quadrotors general third order equation is compared with each other and the coefficient values of the controller are obtained according to the comparison. The effectiveness of the proposed characteristic equation results demonstrated in trajectory tracking performance of quadrotor. In addition to this, comparison between reference characteristic equation and proposed characteristic equation results observed in the same figures. The proposed controller results demonstrate smaller steady state error, smaller oscillation and more precise flight tracking performance with respect to the reference study. Thus, proposed characteristic equation for SOSMC proved its robustness against disturbance rejection and yaw angle deflection inside the trajectory.

For a future work, our aim is to design this controller structure on a real quadrotor system and test trajectory tracking performance.

\section{References}

[1] Frankelius, P., Norrman, C. and Johansen, K., "Agricultural Innovation and the Role of Institutions: Lessons from the Game of Drones", J. Agric. Environ. Ethics, pp.681-707, 2017

[2] Kim, J., Gadsden, S. A., and Wilkerson, S. A., "A Comprehensive Survey of Control Strategies for Autonomous Quadrotors", Canadian Journal of Electrical and Computer Engineering, 43(1), 3-16, 2019

[3] Kumar, S.G. and Shukla, D.P., "Application of drone for landside mapping, dimension estimation and its 3D reconstruction", Journal of the Indian Society of Remote Sensing, pp.903-914, 2018

[4] Liang, X., Fang, Y., Sun, N. and Lin, H., "Nonlinear Hierarchical Control for Unmanned Quadrotor Transportation Systems", IEEE Transactions on Industrial Electronics, Vol.65, No.4, pp. 3395-3405, 2018

[5] Laszlo, B., Agoston, R. and Xu, Q., "Conceptual Approach of Measuring the Professional and Economic Effectiveness of Drone Applications Supporting Forest fire Management", Proc. Eng., 211 8-17, 2018

[6] Madjid, M.Y.A., Vandeginste, V., Hampson, G., Jordan, C.J. and Booth, A.D., "Drones in carbonate geology: Opportunities and challenges, and application in diagenetic dolomite geobody mapping", Mar. Pet. Geol., 91 723-734, 2018

[7] Han, T., Chi, M., Guan, Z.-H., Hu, B. and Xiao, J.-W., Huang, Y., "Distributed Three-Dimensional Formation Containment Control of Multiple Unmanned Aerial Vehicle Systems", Asian J. Control, 2017, Vol. 19, pp. 1103-1113

[8] Dierks, T., and Jagannathan, S., “Output feedback control of a quadrotor UAV using neural networks", IEEE transactions on neural networks, 21(1), 50-66., 2009

[9] Mo, H. and Farid, G., "Nonlinear and Adaptive Intelligent Control Techniques for Quadrotor UAV - A
Survey", Asian Journal of Control, Vol.21, No.2 pp.9891008, 2019

[10] Hassanalian, M., and Abdelkefi, A., "Classifications, applications, and design challenges of drones: A review", Progress in Aerospace Sciences (pp. 99-131), 2017

[11] Bolandi, H., Rezaei, M., Mohsenipour, R., Nemati, H., and Smailzadeh, S. M., "Attitude control of a quadrotor with optimized PID controller", Intelligent Control and Automation, 4(03), 335, 2013

[12] Argentim, L. M., Rezende, W. C., Santos, P. E., and Aguiar, R. A., "PID, LQR and LQR-PID on a quadcopter platform", International Conference on Informatics, Electronics and Vision (ICIEV), pp. 1-6, 2013

[13] Bouabdallah, S., Noth, A., and Siegwart, R., "PID vs LQ control techniques applied to an indoor micro quadrotor", IEEE/RSJ International Conference on Intelligent Robots and Systems (IROS), IEEE Cat. No. 04CH37566, Vol. 3, pp. 2451-2456, 2004

[14] Lippiello, V., Ruggiero, F., and Serra, D., "Emergency landing for a quadrotor in case of a propeller failure: A backstepping approach", IEEE/RSJ International Conference on Intelligent Robots and Systems, pp. 47824788, 2014

[15] Liu, J.K. and Wang, X.H., "Advanced Sliding Mode Control for Mechanical Systems: Design, Analysis and MATLAB Simulation", Springer, Tsinghua University Press, Berlin Beijing, 2012

[16] Razmi, H. and Afshinfar, S., "Neural network-based adaptive sliding mode control design for position and attitude control of a quadrotor UAV" in Aerospace science and technology, (pp. 12-27), 2019

[17] Tilki, U. and Erust, A.C., "Higher Order Sliding Mode Control of Four Rotor Unmanned Aerial Vehicle", International Science, Mathematics and Engineering Sciences Congress, (pp. 189-202), İzmir, 2019

[18] Xu, R. and Ozguner, U., "Sliding mode control of a quadrotor helicopter", Proceedings of the 45th IEEE Conference on Decision and Control, pp. 4957-4962, 2006 [19] Yang, Y. and Yan, Y., "Attitude regulation for unmanned quadrotors using adaptive fuzzy gainscheduling sliding mode control", Aerospace Science and Technology, 54, 208-217, 2016

[20] Zhang, E. H., Xiong, J. J. and Luo, J. L., "Second order sliding mode control for a quadrotor UAV" ISA transactions, 53(4), 1350-1356, 2014 